David Swann BSc FRCAnaes, Patricia Houston MD FRCPC, Jeff Goldberg MD FRCPC

\title{
Audit of intensive care unit admissions from the operating room
}

\begin{abstract}
An audit of 265 intensive care unit (ICU) admissions from the operating room was performed for the year 1991. In a quality assurance exercise we identified 34 unanticipated ICU admissions (UIAs) by a retrospective peer review of the medical charts. Of these UIAs, 16 were deemed predictable and seven preventable. Five of the seven potentially preventable UIAs were judged to have had inappropriate intravenous fluid management. This has prompted changes in our education programme. In an assessment of our resource management, we evaluated prospectively collected data on the Apache II scores on the day of admission, the incidence of ICU-specific interventions, length of stay in ICU, and outcomes. ICU-specific interventions were not initially required in $36 \%$ of admissions and these patients had a low risk (1.1\%) of eventually requiring ICU-specific interventions. In comparison with patients requiring ICU-specific interventions, they had lower Apache II scores (10.2 vs 13.1), shorter ICU stays (medians of one vs two days), lower ICU mortality (0 vs $8.2 \%$ ), $P<0.05$, but hospital mortality was not different (7.4 vs 15.3\%). This audit has prompted reorganisation of our intensive care services, so that patients not requiring ICU-specific interventions will be managed in an intermediate care area with nurse:patient ratios of $1: 3$ or 4 , in comparison with 1:1 or 2 ratios in the intensive care area.
\end{abstract}

Une vérification de 265 admissions dirigées de la salle d'opérations vers l'unité des soins intensifs (SI) a été réalisée pour l'année 1991. Lors d'un exercice d'appréciation de la qualité de lacte médical, nous avons identifié 34 admissions aux SI non prévisibles lors d'une étude rétrospective de révision des dossiers médicaux. De ces admissions non anticipées, seize furent jugées prévisibles et sept évitables. Dans cinq des sept admissions considérées comme évitables, un déséquilibre liquidien était en cause. Ceci a provoqué des changements à notre pro-

\section{Key words}

AUDIT: anaesthesia;

INTENSIVE CARE.

From the Department of Anaesthesia, The Toronto Hospital, Western Division, 399 Bathurst St, Toronto, Ontario, M5T 2S8 Address correspondence to: Dr. Patricia Houston. Accepted for publication 9th October, 1993. gramme d'enseignement. Dans l'évaluation de l'utilisation des ressources, nous avons évalué de façon prospective les données récoltées de scores Apache II le jour de l'admission, lincidence des interventions spécifiques à une unité SI, la durée et le bilan du séjour aux SI. Des interventions spécifiques aux SI ne furent pas initialement requises dans $36 \%$ des admissions et ces malades avaient un faible taux de probabilité d'interventions spécifiques ultérieures. En comparaison avec des patients nécessitant ces interventions, ils avaient des scores Apache II plus bas (10,2 vs 13,1), des durées de séjour plus court (médiane 1 vs 2 jours), et un taux de mortalité aux SI favorable (0 vs 8,2\%) P< 0,05 , mais par contre une mortalite hospitalière non signifcativement différente $(7,4$ vs $15,3 \%)$. Cette vérification a nécessité une réorganisation de nos services de SI de sorte que les patients qui n'ont pas besoin d'intervention spécifiques aux SI sont traités dans des zones de soins intermédiaires comportant un rapport nurse:patient de 1:3 ou 4, au lieu de 1:1 ou 2 dans une zone de SI.

Escalating costs and limitations on health care budgets have prompted recent interest in medical audit. Medical audit has been defined as "the systematic, critical analysis of the quality of medical care, including the procedures used for diagnosis and treatment, the use of resources, and the resulting outcome and quality of life for the patient." The aims of audit are to assure quality of clinical practice as well as efficient resource management. ${ }^{2}$ These aims can be relatively easily achieved in intensive care units (ICUs), where the large database generated from admissions allows analysis, the development of a plan of action and its implementation. These are the key stages of a continual audit process. ${ }^{3}$

Review of unanticipated intensive care unit admissions (UIAs) may identify patterns of care requiring improvement, although the usefulness of this process has recently been questioned. ${ }^{4,5}$ The high cost of intensive care has been an impetus to the scrutinisation of its organization and delivery. There are suggestions that patients who only require monitoring would do just as well in intermediate care units. $^{6-8}$

The aims of this study were to evaluate one year's intensive care admissions from the operating room (OR). As a quality control exercise, we wished to quantify un- 
anticipated admissions (UIAs), those that could have been predicted, and those that could have been avoided. We evaluated our resource management by quantifying the OR admissions who received intensive care-specific interventions. Also, the severity of the patients' illnesses and outcomes was determined.

\section{Methods}

\section{Study setting and population}

The Medical-Surgical ICU at the Toronto Western Division of The Toronto Hospital is a 14-bedded unit. The ICU is staffed by five attending critical care consultants who oversee all admissions. It is the only area in the hospital where postoperative patients can be monitored invasively. The average bed occupancy rate is $86 \%$. There are separate neurosurgical intensive care and coronary care facilities. Surgical services include general, thoracic, orthopaedic, gynaecological, otolaryngological, and ophthalmic subspecialities. There is a daycase surgical unit.

There was a total of 679 ICU admissions for 1991, including 342 medical admissions, and 337 surgical admissions. We studied 265 consecutive postoperative patients admitted to ICU from January 1 to December 31, 1991.

\section{Data collection and analysis}

The data analysed in the study came from two sources: an ICU audit database and the medical chart.

The audit database is maintained by a dedicated research assistant on a Macintosh IIsi desktop computer, using programmable software (FileMaker Pro, Claris Corp.). These data were collected prospectively by ICU residents and the research assistant, and were reviewed for accuracy by the first author. The information included: the emergency or elective status of the operation; the Apache II score for the first $24 \mathrm{hr}$ of ICU admission and diagnosis; the length of stay in ICU; the daily incidence of ICU-specific interventions and the ICU and hospital outcomes. The following procedures were considered ICU-specific: intracranial pressure monitoring, tracheal intubation within the previous $24 \mathrm{hr}$, artificial ventilation, placement of a pulmonary artery catheter, inotropic or vasoactive drug infusion, renal dialysis and epidural drug administration. (Local nursing policy dictates that patients with epidural catheters for postoperative analgesia are admitted to ICU). A predicted mortality rate derived from the Apache II score and diagnosis was calculated for each patient. ${ }^{9}$ Medical chart review by the first author characterized the nature of the ICU admission, as either anticipated or unanticipated. The admission was considered unanticipated if it was precipitated by an unexpected, adverse perioperative event. The charts of these UIAs were then reviewed independently by all the authors to determine which could have been predictable had the anaesthetist taken due consideration of the nature of the patient's disease, surgery and anaesthetic and which were preventable had appropriate perioperative care been taken. A meeting of all the authors then formed a consensus.

These opinions were formed from entries made by anaesthetists, surgeons and admitting intensivists in the anaesthetic, OR and clinical records.

Statistical analysis was performed using StatView II software (Abacus Concepts, Inc.). Significance testing employed Mann-Whitney rank sum for real data and $\chi^{2}$ tests for categorical data.

\section{Results}

Excluding neurosurgical procedures, 18,555 operations were performed in 1991. These included 8,546 daycase operations. There were 265 postoperative ICU admissions, including two from the daycase unit.

Thirty-four admissions were unanticipated. Of these, 16 were judged to be predictable and seven preventable (Table I). One hundred and fifty-two patients had emergency operations. They had higher Apache II scores, longer lengths of ICU stay, greater incidences of ICUspecific interventions and higher ICU and hospital mortality rates than patients undergoing elective procedures (Tables II and III), $P<0.05$.

Thirty-four admissions were unanticipated. There operation status, Apache II scores, length of stay, use of ICU-specific interventions, hospital and ICU outcomes did not differ from the anticipated admissions (Tables II and III), $P<0.05$.

Seven unanticipated admissions were judged as potentially preventable. Their operation status, Apache II scores, length of stay, use of ICU-specific interventions and outcomes did not differ from non-preventable admissions. There were no ICU deaths in this group (Tables II and III)

Ninety-five patients (35.8\%) did not receive any ICUspecific interventions. They had low Apache II scores and shorter lengths of ICU stay. There were no ICU deaths in this group. Although the hospital mortality was less than that of patients who received ICU-specific therapy, this did not achieve statistical significance (Tables II and III).

Only one of these patients went on to require ICUspecific interventions. He was a 30 -yr-old multiple trauma victim who developed fat embolism syndrome on his second day of admission. His trachea was intubated, his lungs ventilated and a pulmonary artery catheter was placed to assist with fluid management. Subsequently he made a full recovery. 
TABLE I The rationale of the predictability and preventability of the UIAs

\begin{tabular}{|c|c|c|c|}
\hline Patient & Predictability & Preventability & Rationale \\
\hline $\mathbf{I}$ & \multirow[t]{14}{*}{ Unpredictable } & \multirow[t]{14}{*}{ Non-preventable } & Pulmonary embolism after knee surgery \\
\hline 2 & & & Ischaemic changes in intraoperative ECG \\
\hline 3 & & & Intraoperative hypoxaemia with left lung collapse \\
\hline 4 & & & Ischaemic changes in intraoperative ECG \\
\hline 5 & & & Pseudocholinesterase deficiency \\
\hline 6 & & & Acute atrial fibrillation \\
\hline 7 & & & Postoperative respiratory arrest \\
\hline 8 & & & Myocardial infarction with shock \\
\hline 9 & & & Hypoxaemia after long bone fixation \\
\hline 10 & & & Myocardial infarction with stroke \\
\hline 11 & & & Intraoperative hypoxaemia with left lung collapse \\
\hline 12 & & & Aspiration pneumonitis \\
\hline 13 & & & Myocardial infarction \\
\hline 14 & & & Anaphylactoid drug reaction \\
\hline 15 & \multirow[t]{13}{*}{ Predictable } & \multirow[t]{13}{*}{ Non-preventable } & Chronic heart failure, laparotomy for perforated viscus \\
\hline 16 & & & Acute pulmonary oedema, severe chronic heart failure \\
\hline 17 & & & Preoperative lung collapse and hypoxaemia \\
\hline 18 & & & Stridor because of mediastinal tumour \\
\hline 19 & & & Severe COPD, laparotomy \\
\hline 20 & & & Preoperative hypoxaemia, severe chronic heart failure \\
\hline 21 & & & New ischaemic changes in preoperative ECG, hip fracture \\
\hline 22 & & & Multiple trauma, massive transfusion \\
\hline 23 & & & Stridor because of neck abscess \\
\hline 24 & & & Severe COPD, laparotomy \\
\hline 25 & & & Preoperative pneumonia \\
\hline 26 & & & Inadequate preoperative assessment of respiratory failure \\
\hline 27 & & & Preoperative pneumonia \\
\hline 28 & \multirow[t]{4}{*}{ Unpredictable } & \multirow[t]{4}{*}{ Preventable } & Inadequate $\dot{w}$ fluid management \\
\hline 29 & & & Traumatic intubation with airway bleeding \\
\hline 30 & & & Inadequate $\dot{N}$ fluid management \\
\hline 31 & & & Inadequate $\dot{\boldsymbol{N}}$ fluid management \\
\hline 32 & \multirow[t]{3}{*}{ Predictable } & \multirow[t]{3}{*}{ Preventable } & Dialysis patient, pulmonary oedema after excess $i v$ fluid \\
\hline 33 & & & Inadequate $i v$ fluid management \\
\hline 34 & & & Inadequate $\dot{\alpha}$ fluid management \\
\hline
\end{tabular}

\section{Discussion}

This audit has provided information which led to changes in our data gathering and evaluation. It has also been a useful exercise in quality control and in assessment of our resource management. Firstly, it has shown how we might improve our data gathering. Ensuring data accuracy is of great importance in any audit exercise. Early in this study it was obvious that there were many omissions in our prospectively collected database regarding interventions that patients received. Review of patients' charts rectified this for the purposes of this study. However, daily review of the patients' datasheets by the ICU clinical fellow now ensures data accuracy. We are also considering adoption of the therapeutic intervention scoring system to enable better evaluation of resource utilization. ${ }^{10}$
We have quantified UIAs as a quality control measure of anaesthetic care in our hospital. In our study 34 postoperative ICU admissions were anticipated. These UIAs occurred in 18,555 operations ( $0.18 \%$ incidence). Seven were deemed preventable, and 16 predictable. Few studies have examined the preventability of UIAs. Leigh and Tytler" identified 46 ICU admissions diagnosed as "anaesthetic complications" occurring in 109,060 operations ( $0.04 \%$ incidence). Fourteen were judged to be predictable or avoidable. Cullen et al. ${ }^{5}$ did not identify any remediable patterns of care in 71 UIAs after 17,093 operations ( $0.42 \%$ incidence), and hence questioned the utility of UIAs as a generic screen for quality assurance.

The wide variation in the incidences of UIAs in these studies is not surprising given different methods of data collection and the subjective nature of peer review, as 
TABLE II Apache II score on day of admission (mean and range), length of ICU stay in days (median and range), and incidence of ICU-specific interventions ( $n$ and \%) of patients admitted to the ICU from the OR. Data for sub-groups of elective/emergency operations, anticipated/unanticipated admissions, preventable/non-preventable UIAs, and ICU/no ICU-specific interventions are also presented.

\begin{tabular}{lllll}
\hline & $n(\%)$ & Apache II & $\begin{array}{l}\text { ICU stay } \\
\text { (days) }\end{array}$ & $\begin{array}{l}\text { ICU-specific } \\
\text { interventions (\%) }\end{array}$ \\
\hline All patients & $265(100)$ & $12.1(0-38)$ & $1(1-119)$ & $170(64.2)$ \\
Elective operation & $152(57.4)$ & $10.8(0-31)$ & $1(1-28)$ & $88(57.9)$ \\
Emergency operation & $113(42.6)$ & $13.8(0-38)^{*}$ & $2(1-119)^{*}$ & $82(72.6)^{*}$ \\
Anticipated ICU Admission & $231(87.2)$ & $12.1(0-38)$ & $1(1-48)$ & $151(88.8)$ \\
Unanticipated ICU admission & $34(12.8)$ & $11.6(0-24)$ & $1.5(1-119)$ & $19(55.9)$ \\
Preventable UIA & $7(0.03)$ & $11.0(6-20)$ & $1(1-3)$ & $4(57.1)$ \\
Non-preventable UIA & $27(0.1)$ & $11.7(0-24)$ & $2(1-119)$ & $15(55.6)$ \\
ICU intervention & $170(64.2)$ & $13.1(0-38)$ & $2(1-119)$ & - \\
No ICU-specific intervention & $95(33.8)$ & $10.2(0-26) \dagger$ & $1(1-12) \dagger$ & - \\
\hline
\end{tabular}

$* P<0.05$ compared with elective patients.

$\dagger P<0.05$ compared with patients who received ICU-specific interventions.

TABLE III Predicted (PMR), ICU and hospital mortality rates of patients admitted to ICU from the OR. Data for sub-groups of elective/emergency operations, anticipated/unanticipated admissions, preventable/ non-preventable UIAs, and ICU-specific intervention/no ICU-specific intervention are also presented.

\begin{tabular}{lllll}
\hline & $n$ (\% of total) & PMR (\%) & ICU deaths (\%) & $\begin{array}{l}\text { Hospital deaths } \\
(\%)\end{array}$ \\
\hline All patients & $265(100)$ & 16.5 & 5.3 & 12.4 \\
Elective operation & $152(57.4)$ & 12.5 & 1.3 & 5.9 \\
Emergency operation & $113(42.6)$ & $22^{*}$ & $10.6^{*}$ & $21.3^{*}$ \\
Anticipated ICU admission & $231(87.2)$ & 16.9 & 6.1 & 13 \\
Unanticipated ICU admission & $34(12.8)$ & 13.9 & 0 & 8.8 \\
Preventable UIA & $7(0.03)$ & 10.9 & 0 & 14.2 \\
Non-preventable UIA & $27(0.1)$ & 14.6 & 0 & 7.4 \\
ICU intervention & $170(64.2)$ & 19.4 & 8.2 & 15.3 \\
No ICU-specific intervention & $95(33.8)$ & $11.4 \dagger$ & $0 \dagger$ & 7.4 \\
\hline
\end{tabular}

${ }^{*} P<0.05$, compared with elective patients

$\dagger P<0.05$, compared with patients who received ICU-specific interventions.

a method of data evaluation. However, our study has been useful because it identified adverse outcomes (i.e., UIAs). We have analyzed the reasons behind their occurrence and found a potentially remediable pattern of care. However, given the low incidence of adverse clinical outcomes we accept that not all ICUs will identify such trends.

Six out of seven patients who were judged to have had a preventable UIA were given inappropriate intravenous fluid therapy. This pattern of care requires improvement. We have presented these findings to the anaesthetic staff at an audit meeting and have planned grand rounds on the management of perioperative fluid administration. It remains to be seen if these educational tactics will have an impact on the incidence of UIAs.

This study has provided information regarding resource management. Thirty-six percent of postoperative admis- sions to our unit did not require ICU-specific interventions. This is of the same order as the $20-40 \%$ incidence of low-risk monitoring admissions reported by other ICUs. ${ }^{6-7}$ We have also confirmed that such patients have a low risk of eventually requiring ICU-specific interventions and have a good outcome in terms of hospital mortality.

Such data raise questions about the organization of ICUs. The provision of an intermediate care facility for low-risk monitoring patients would seem to be an efficient addition to the services of the ICU and the general wards. A nurse to patient ratio of $1: 3$ or $1: 4$ in an intermediate care unit would represent considerable savings over the 1:1 or 1:2 ratios in intensive care. Oye and Bellamy ${ }^{7}$ have pointed out that such changes would increase the burden on ICU nurses and could have an adverse effect on staff morale. Civetta ${ }^{12}$ has also objected to the exclusion of 
low-risk monitoring patients from ICU because of the possibility of the later development of complications requiring early and effective intervention. Our ongoing proposal is to admit low-risk monitoring patients to a separate room in the ICU, which would function as an intermediate care area. Nurses would rotate between the intensive care and intermediate care areas, maintaining variety in their workload. The ICU medical staff would also attend the patients in the intermediate care area, and patients would rapidly receive ICU-specific interventions when indicated. There would be no savings in labour costs, but we would be more efficient in allocating our resources at a time when we are unable to meet all tertiary referrals to our unit.

There are no studies assessing the impact of intermediate care units. A prospective, randomized clinical trial would be difficult to perform. Outcome measures such as death or major morbidity resulting in ICU admissions occur so infrequently that a large multi-centre study would be required to generate enough power for valid conclusions.

In summary, audit of postoperative ICU admissions has provided valuable insights into our standards of anaesthetic practice and utilization of intensive care resources. This has allowed us to implement changes in our practice. We will continue to assess the impact of these changes.

\section{Acknowledgements}

We would like to thank Dr. Rose-Marie Chua and Mr. Bob Pearse for their help with data collection.

\section{References}

1 Ellis $B W$, Sensky $T$. A clinician's guide to setting up audit. BMJ 1991; 302: 704-7.

2 Vestrup JA. Critical care audit (editorial). Can J Anaesth 1992; 39: 210-3.

3 Byrick RJ, Caskennette GM. Audit of critical care: aims, uses, costs and limitations of a Canadian system. Can $\mathbf{J}$ Anaesth 1992; 39: 260-9.

4 Sanazaro PJ, Mills DH. A critique of the use of generic screening in quality assessment. JAMA 1991; 265: 1977-81.

5 Cullen DJ, Nemeskal R, Cooper JB, Zaslavsky A, Dwyer $M J$. Effect of pulse oximetry, age, and ASA physical status on the frequency of patients admitted unexpectedly to a postoperative intensive care unit and the severity of their anesthesia-related complications. Anesth Anal 1992; 74: 181-8.

6 Henning RJ, McClish D, Daly B, Nearman H, Franklin $C$, Jackson $D$. Clinical characteristics and resource utilization of ICU patients: Implications for organization of intensive care. Crit Care Med 1987; 15: 264-9.

7 Oye RK, Bellamy PE. Patterns of resource consumption in medical intensive care. Chest 1991; 99: 685-9.

8 Luce $J M$. Improving the quality and utilization of critical care. QRB February 1991: 42-7.

9 Knaus WA, Draper EA, Wagner DP, Zimmerman JE. Apache II: a severity of disease classification system. Crit Care Med 1985; 13: 818-829.

10 Keene AR, Cullen $D J$. Therapeutic intervension scoring system: Update 1983. Crit Care Med 1983; 11: 1-3.

11 Leigh JM, Tytler JA. Admissions to the intensive care unit after complications of anaesthetic techniques over 10 years. 2. The second 5 years. Anaesthesia 1990; 45: 814-20.

12 Civetta JM. "New and improved" scoring systems (editorial). Crit Care Med 1990; 18: 1487-90. 